\title{
Unit cost analysis of training and deploying paid community health workers in three rural districts of Tanzania
}

\author{
Kassimu Tani ${ }^{1 *}$, Amon Exavery ${ }^{1}$, Colin D. Baynes ${ }^{1,2}$, Senga Pemba ${ }^{3}$, Ahmed Hingora ${ }^{1}$, Fatuma Manzi ${ }^{1}$,
} James F. Phillips ${ }^{2}$ and Almamy Malick Kanté ${ }^{1,2}$

\begin{abstract}
Background: Tanzania, like other African countries, faces significant health workforce shortages. With advisory and partnership from Columbia University, the Ifakara Health Institute and the Tanzanian Training Centre for International Health $(T \mathrm{CIH})$ developed and implemented the Connect Project as a randomized cluster experimental trial of the childhood survival impact of recruiting, training, and deploying of a new cadre of paid community health workers (CHW), named "Wawazesha wa afya ya Jamii" (WAJA). This paper presents an estimation of the cost of training and deploying WAJA in three rural districts of Tanzania.
\end{abstract}

Methods: Costing data were collected by tracking project activity expenditure records and conducting in-depth interviews of TTCIH staff who have led the training and deployment of WAJA, as well as their counterparts at Public Clinical Training Centres who have responsibility for scaling up the WAJA training program. The trial is registered with the International Standard Randomized Controlled Trial Register number (ISRCTN96819844).

Results: The Connect training cost was US\$2,489.3 per WAJA, of which $40.1 \%$ was for meals, $20.2 \%$ for accommodation $10.2 \%$ for tuition fees and the remaining $29.5 \%$ for other costs including instruction and training facilities and field allowance. A comparable training program estimated unit cost for scaling-up this training via regional/district clinical training centres would be US\$ 833.5 per WAJA. Of this unit cost, $50.3 \%$ would involve the cost of meals, $27.4 \%$ training fees, $13.7 \%$ for field allowances, $9 \%$ for accommodation and medical insurance. The annual running cost of WAJA in a village will cost US\$ 1.16 per capita.

Conclusion: Costs estimated by this study are likely to be sustainable on a large scale, particularly if existing regional/district institutions are utilized for this program.

Keywords: Community health worker, Training cost, Operation cost, Primary care, Tanzania

\section{Background}

Tanzania, like many other African countries, is compelled to confront its high burden of disease with a low ratio of population density of health workers (HW) [1, 2]. Human resource shortages rank among the most prominent challenges that must be addressed if health system performance is to be improved [1, 3]. A confluence of factors contribute to the manpower crisis: rapid population growth, health system resource constraints and inadequate worker training [4], emigration of health

\footnotetext{
* Correspondence: ktani@ihi.or.tz

${ }^{1}$ Ifakara Health Institute, P.O. Box 78373, Dar es Salaam, Tanzania

Full list of author information is available at the end of the article
}

professionals, or shifting employment from the health sector to other pursuits within the country [5]. In subSaharan Africa, these pervasive problems are exacerbated by systems constraints that vary by country, but typically include lack of capacity to absorb and deploy health workers, inadequate investments in pre-service training, shifts to other non-health professions that are motivated by low levels of compensation and by the workforce effects of the high prevalence of HIV/AIDS $[4,6]$.

The regional toll of these problems is striking. In 2006, the World Health Organization (WHO) estimated that Africa had only 2.3 healthcare workers per 1,000 population compared with 4.3 for Southeast Asia and 24.8 for North 
America [7]. At 1.35 healthcare workers per 1,000 population and 1 physician per 25,000 population in 2010, Tanzania ranks below the average health professional population density for Africa $[8,9]$ and far below the WHO recommendation of 1 physician per 1,000 population. There is a little doubt that this health workforce shortage has constituted a key barrier to achieving MDGs 4 and 5 in Tanzania where 1 in 9 children die before the age of five $[5,10]$, maternal mortality is 432 per 100,000 live births $[11,12]$, and shortages of medicines and supplies, inadequate infrastructure and poor patient transportation systems amplify the effects of manpower shortage [13].

Several influential observers have argued that this manpower shortage can be addressed by tackling existing inefficiencies in the health system, such as improve limited capacity for planning, deploying and monitoring health staff and utilizing community health workers (CHW) to provide primary health care services [14-16]. In particular, the development of CHWs can accelerate health services utilization and improve the overall effectiveness of primary health care $[14,17]$ as they are promoting and sensitizing the community on the importance of seeking health care at health facilities. Bhutta and his colleagues $[18,19]$ and the One Million CHWs Campaign [18, 19] demonstrated and advocated that the deployment of well trained, supplied, supervised and paid CHWs can contribute significantly to improvements of maternal, newborn, and child health $(\mathrm{MNCH})$ as well as survival.

Despite a number of developments and interventions from various development partners in deploying voluntary HW in rural communities, Tanzania continues to faces the challenge of integrating an appropriately trained cadre as part of the national primary health care system [20]. Considerable evidence has shown that home visitation contributes significantly to improving population health, particularly in settings with extreme shortages of capable health professionals $[1,21,22]$. The quality of care and sustainability of $\mathrm{CHW}$ programs were generally found to be poor due to lack of continuing professional development and insufficient supervision [23, 24]. However, all CHW programs relied upon unpaid volunteers, most of whom had limited training and specific disease focused roles [25].

Rationale for training and deploying a new cadre of $\mathrm{CHW}$ The Tanzania Ministry of Health and Social Welfare (MoHSW) instituted the Primary Health Services Development Programme 2007-2017 (MMAM - Swahili acronym) to address the manpower shortage. The MMAM programme aims to strengthen interactions between health facilities and communities by having a cadre of HW based at a community level [26]. Through MMAM, the MoHSW set an objective to reduce the maternal mortality ratio from 578 maternal deaths per 100,000 live births in 2000 to 220 per 100,000 in 2012, and improve newborn care. Nevertheless, by 2012, mortality had only declined to 432 per 100,000 live births [12]. Among the strategies included in $M M A M$ was the deployment of CHWs to every village [12, 27]. Although this strategy is in the process of been implemented nationally, it is currently in the stages of training CHWs in a number of public and private institutions. The CHW policy has already been developed and was signed in 2014.

Evidence from CHW programs emphasize community ownership in selecting these workers from the communities they will serve to maintain retention, acceptability and environment awareness [28]. Yet despite efforts in developing strategies for recruitment and deployment of CHWs, there is little information on the full cost of training, deploying and running full-time, paid CHWs on a wide scale. Specifically, most of the CHWs that have been deployed in Tanzania received short term training and contracts for specific short-term interventions [29].

Based on the above concerns, the Ifakara Health Institute (IHI), the Tanzanian MoHSW, the Tanzanian Training Center for International Health (TTCIH) and Columbia University's Mailman School of Public Health (CU-MSPH) launched in 2011 a CHW program known as Connect to evaluate the childhood survival impact of introducing a cadre of paid CHWs known as "Community Health Agents," which translates into Swahili as "Wawezashaji wa Afya ya Jamii" (WAJA) into local health systems. The aim of this paper is to estimate the annual unit cost for pre service training, deployment, and maintaining paid CHWs in Tanzania so as to enable policymakers to determine the financial implications of integrating this cadre into the national primary health care system [30].

\section{Method}

\section{Project design and approach}

Connect operates as a randomized cluster trial (RCT) allocating 50 villages to intervention (villages receiving WAJA) and 51 to comparison (villages not receiving WAJA). All 101 villages were located in Kilombero, Ulanga and Rufiji districts of Tanzania where the IHI Health and Demographic Surveillance Systems (HDSS) monitored population dynamics since 1996 to allow for an evaluation of the project's impact on mortality $[31,32]$. Further, the Connect economic evaluation aims to assist the MoHSW to determine and model the cost of recruitment, training and deployment of WAJAs as envisioned in the MMAM [27] and corresponding ongoing policy development.

By August 2012, 113 WAJA were trained and deployed in the 50 villages of intervention. Training and deployment were pursued in two phases, with WAJA deployed to villages in August 2011 (Batch one $=57$ WAJA) and 
August 2012 (Batch two $=56$ WAJA). Analysis included two phases of WAJAs deployment. The project provides funds to districts for human resources, and supplies are directly provided by the project. WAJAs link communities to the health system by providing basic curative and preventive health services, health education, promotion and referral to the health care facilities [32].

\section{Recruitment of WAJA}

Recruitment of WAJAs involved community sensitization that informed the community about the project and necessary qualifications for selected individuals for WAJA training. Selection criteria included residence in the community, at least four years of secondary education, and minimum pass in at least two subjects. Other recruitment activities included posting advertisements to notice boards and other important places in communities. Applicants sent their applications to the village executive officer. With the help of the district education office, the village committee screened applicants' certificates. At a subsequent meeting, qualified candidates were asked to brief community members about their suitability for the position, after which community members voted to select the WAJA(s) for their area. One to four WAJAs were selected from each community, based on village population size.

\section{Training design and process}

The WAJAs training was held at the TTCIH and all students from Rufiji, Ulanga and Kilombero settled at the training center in Ifakara town. The training spanned nine months and was divided into two sections. The first involved theoretical training that included basic clinical skills, community health skills such as communication and advocacy, counseling, disease prevention, health education, nutrition, primary health care and human biology. A field practice component was also incorporated in the first section of the training, conducted in the villages surrounding the training institution with support from WAJA trainers. The second training section was a field attachment, done in the WAJAs' home villages. This involved practicing their skills under the close supervision of trainers and a clinical officer from the nearest health facility. WAJAs were then invited to the TTCIH for a final writing and oral examination to test competencies gained during the training. The TTCIH incurred a number of preliminary costs when preparing to accommodate the training such as the renovation of dormitories, hiring a new building for dormitories outside the school, developing curriculum and capacity building for trainers.

\section{WAJA's deployment}

Deployment proceeded immediately after WAJA graduated and passed their final examination. Community members organized a village meeting where the project presented a fully trained WAJA with the necessary equipment (bicycle, mobile phone, weighing machines, flip charts, and malaria rapid diagnostic test kits) and medicines (Amoxycillin, Artemeter Lumefantrine (ALu) as an Artemesinin-based Combination Therapy (ACT) known as Coartem, oral rehydration salts (ORS), Zinc oxide plaster etc.). Communities provided a cupboard for storing WAJA medicines and supplies. The district health administration was responsible for providing WAJA with an employment appointment letter and administering all human resource matters, including WAJA salaries (channeled to the district by the project, but paid by district authorities) and social security benefits. WAJAs were supervised by intervention coordinators from the project and by the district health administration. A selected HW from a nearby health facility provided technical advice and a village executive officer oversaw WAJA activities at the community level. These supervisors met with WAJA at least once every three months. WAJA phones were also connected to close user group service (CUG), allowing free calls between them and their supervisors for immediate support.

\section{Data sources}

Data on training costs were obtained from the actual expenditures related to schooling costs at the TTCIH. These were extracted from expenditure accounts and improved by in-depth interviews with TTCIH management to provide necessary clarifications. All information was confirmed by records review and interviews of relevant TTCIH and Connect project staff. Data on the cost of deployment and annual operation costs of WAJAs were extracted from the Connect project records. Information was gathered from expenditure records of Connect interventions and the actual cost incurred for specific activities like training, salary, supervision, medicines and supplies. The number of WAJAs per village and village population size were obtained from project records. Resources expended for on year of WAJA operations were tracked from the expenditure accounts and records of quantities of items supplied directly to the WAJAs. The national population and village data were drawn from the Tanzania 2012 Census.

The relative training costs of comparable MoHSW operations were gathered from the Clinical Officer Training Centre of Kilosa in Morogoro, a public institution that specializes in two-year training certificates for Assistant Clinical Officers, and three-year diplomas for the lowest level paramedics, Clinical Officers, who provide preventive and treatment services at primary health care facilities. Public Clinical Officer Training Centres were selected due to their future responsibility in scaling up the WAJA training program should it be adopted as policy. In-depth interviews with management and financial officers were conducted at the Clinical Officer Training Centre. These, 
in combination with records review, helped determine the costs of all pre-service training, logistics and operations associated with certificate and/or diploma procedures for one academic year. Information from the Kilosa Training Centre in Morogoro Region, the public institution that trains the lowest level of paramedics, was similarly gathered. The training costs of Assistant Clinical Officers were ultimately used as a benchmark, as this cadre is most similarly comparable to the education level required for the WAJAs.

\section{Data analysis}

Analysis involved valuing each resources used in every activity related to WAJA training, deployment and annual running costs. Interview responses were coded and grouped into specific groups to clarify mentioned categories. Actual costs from the records were then combined based on this information.

The unit training cost of WAJA was calculated as the total cost of establishing WAJAs divided by the number of WAJAs trained by the project. The unit training cost of Assistant Clinical Officers was calculated as the annual cost of training divided by the number of trainees.

Modeling scale-up training cost using project expenditure and clinical training centre information followed, and was developed according to seven assumptions :i) The training of WAJA will be undertaken by existing government training institutions and will be within their existing competence; ii) Tuition allowance, training facilities, and utilities are to be included into an overall tuition fee; iii) Curriculum and identity card costs are included in tuition fees; iv) Meals are provided for students undergoing training; v) Transport costs for WAJA to travel to training and return to their villages are not included in the estimates; vi) Students will have two months of field attachment; and vii) The district health system is the unit of planning. After deploying WAJAs to the health system at the village level, resources to run the program for a full year were tracked and related costs recorded to determine annual running costs for the program.

Our estimation was based on the number of WAJAs required to serve: 1) A standard-sized district in Tanzania; and 2) The entire country. This estimate was based on the population of the villages as assessed in Connect project. Villages with populations less than 1,000 people received 1 WAJA; villages with a population of 1000 to 4000 received 2 WAJAs; villages with a population of 4000 to 7000 received 3 WAJAs; and those with more than 7000 received 4 WAJAs. To determine the standard size of a district, villages in project districts were summed and averaged to have a mean number of villages in a "standard-sized district".

The trial is registered with the International Standard Randomized Controlled Trial Register (number ISRCTN96819844).

\section{Results}

Table 1 presents various program activities related to WAJA training and the unit cost per WAJA trained. Costs are presented in the 2011 equivalent US dollar (US\$) value of the local currency, Tanzanian Shilling (TSH) ${ }^{1}$ at the time of deployment.

The unit cost of the training program was US\$2,489.3 per trainee with the highest percentage (40.1\%) spent on meals. Accommodation during training accounted for $20.2 \%$, tuition fees were $10.2 \%$, and stipends, field allowances and training facilities and utilities accounted for $19.9 \%$ of the total unit training costs. Other costs accounted for $8.5 \%$, and medical insurance for trainees comprised $1.0 \%$ of the total unit cost.

Table 2 shows the equivalent cost of one year of training for an Assistant Clinical Officer in 2011 at the Kilosa Training Centre. The annual unit training cost for an Assistant Clinical Officer was US\$ 731.0, where meals accounted for the highest portion of the total training cost at $55.1 \%$. The field attachment accounted for $15.6 \%$ of the total cost, followed by tuition fees, accommodation, and utilities at $15.3,8.5$, and $5.1 \%$, respectively. Stationery comprised less than $1 \%$ of the total training cost.

As shown in Table 3, the modeled scaling up cost to train a WAJA based on the Kilosa Public Clinical Officer Training Centre is estimated at US\$ 833.50. Half of this cost $(50.3 \%)$ would involve meals, $27.4 \%$ tuition fees, $13.7 \%$ field allowance, $6.0 \%$ accommodation and $2.7 \%$ medical insurance.

Table 4 presents the annual running cost for the 113 WAJAs deployed to the Connect intervention districts, totaling US\$ 407,954 per year. The highest portion of costs were associated with WAJA salaries at $48.3 \%$, followed by drugs/medicines at $35.3 \%$, supporting structures at $14.2 \%$ and medical supplies at $2.3 \%$. The cost of operating one WAJA in a village is US\$ 3,610, which is equal to US\$ 1.16 per capita per year.

Table 1 Unit cost for training a community health agent (WAJA), Connect Project, 2011

\begin{tabular}{lll}
\hline Cost category & $\begin{array}{l}\text { Unit cost (USD) } \\
\text { Per WAJA deployed }\end{array}$ & Percentage (\%) \\
\hline Meals & 997.31 & 40.1 \\
Accommodation & 502.97 & 20.2 \\
Tuition fee & 254.21 & 10.2 \\
WAJA stipend & 199.37 & 8.0 \\
Training facility and utilities & 195.04 & 7.8 \\
Field allowance & 101.99 & 4.1 \\
Medical insurance & 23.86 & 1.0 \\
Curriculum development & 2.34 & 0.1 \\
Other & 212.16 & 8.5 \\
Total Unit Training Cost & $2,489.25$ & 100.0 \\
\hline
\end{tabular}

Source: Connect project WAJA training data 
Table 2 Unit cost for training an assistant clinical officer at a public training centre in Tanzania in 2011

\begin{tabular}{lll}
\hline Cost category & $\begin{array}{l}\text { Unit cost (USD) } \\
\text { Per WAJA deployed }\end{array}$ & Percentage (\%) \\
\hline Meals & 403.0 & 55.1 \\
Field allowance & 114.0 & 15.6 \\
Tuition fee & 112.0 & 15.3 \\
Accommodation & 62.0 & 8.5 \\
Utility & 37.0 & 5.1 \\
Stationary & 4.0 & 0.5 \\
Total Unit Training Cost & 731 & 100.0 \\
\hline
\end{tabular}

Source: Public clinical officer training centre, Kilosa-Morogoro

To scale up WAJA training to a standard district, based on Connect allocation, covering all villages was estimated to cost US\$180,206, which covered training of approximately 216 WAJA. The training to cover the entire country will require training for 27,120 WAJAs. Training is estimated to cost US\$ 0.5 per capita and can be implemented by zones in different batches for a number of years.

\section{Discussion}

We have estimated the unit cost of comprehensive training, deployment and annual running cost of a paid WAJA. The analysis estimates these costs in the current health system structure, and, thereby, costs that offer a potential solution to the shortage of primary health care human resources [33] in Tanzania. Programs elsewhere have recruited newlygraduated students of various levels and trained them for various durations to become CHWs. For example, in India such workers were trained for three months, whereas in Brazil, they were trained for six to eight months prior to their deployment [34]. However, for most such programs, as in Uganda, Ethiopia and Rwanda, the cost of training, deployment and running a CHW remains unexhausted as it has not captured the full package of CHW tasks [17, 23]. However, few studies have pointed out a shadow value for CHW as they work in informal market [35].

Table 3 Modeled training cost based on Connect project and clinical officer training centre

\begin{tabular}{lll}
\hline Cost Category & $\begin{array}{l}\text { Unit cost (USD) } \\
\text { Per WAJA deployed }\end{array}$ & Percentage (\%) \\
\hline Meals & 419.19 & 50.3 \\
Tuition fee & 228.40 & 27.4 \\
Field allowance & 113.98 & 13.7 \\
Accommodation & 49.67 & 6.0 \\
Medical insurance & 22.25 & 2.7 \\
Modeled Unit Training Cost WAJA & 833.49 & 100.0 \\
\hline
\end{tabular}

Source: Calculated by the authors based on scenario of project expenditure and public clinical officer training centre
Table 4 Annual cost of running Connect

\begin{tabular}{lcc}
\hline Cost category & Cost (USD) & Percentage \\
\hline Project costs of program implementation: & \\
Support structure & 57,794 & 14.2 \\
Salary & 196,839 & 48.3 \\
Medicine & 144,020 & 35.3 \\
Supplies & 9,301 & 2.3 \\
Total financial cost & 407,954 & 100.0 \\
Estimated unit costs of program implementation: & \\
Unit annual cost per WAJA & 3,610 & \\
Per capita cost & 1.16 & \\
\hline Source: Connect project running/operation data &
\end{tabular}

This study has estimated the cost of scaling up WAJA training at public training centres to be US $\$ 833.50$ per WAJA, compared with the Connect project actual training cost of US\$ 2,489 per WAJA. The Connect project training was done in an institution that runs in-service training and technical training such as advanced diplomas, degrees and post-graduate diplomas. The scaling up cost is less and provides best proxy as it is derived from the cost of training clinical officers at regional and district training centres. The training profile of these institutions reflects the cost of training primary health care staff who are hired at the minimum education level of four years of secondary education and basic technical education. The running of such training exists at a number of regional training institutions mostly found at regional hospitals and few district hospitals. The training of such workers resembles WAJA training, where the cost of meals, teaching methodology and supporting staff is similar, except its training duration, which is twice as long as that of WAJA. A high proportion of training costs was comprised of meals and accommodation at 57 and $60 \%$ of training costs of the estimated scaling up Assistance clinical officers and WAJA.

The difference between estimated Connect Project costs and estimated program scale-up costs is based on the utilization of existing data on the operating costs of public clinical officer training centres, given prevailing residency, training, and meal expenses. Project expenses of Connect WAJA training involved accommodating students in hired dormitories outside the campus, while at the clinical officer training centre, students stayed in less costly arrangements at dormitories located inside the campus. Thus, if scale-up is based solely in clinical officer training centres under National council for technical education, the implementation costs of WAJA scale-up will be reduced, particularly if existing public college training facilities accommodate students and provide meals. However, estimating the full cost of public sector student training is complicated due to the presence of 
undocumented subsidies that arise from the government and the community to support the institution, such as security and community contributions to building or renovating new infrastructures [36]. Although the WAJA program has incurred far less indirect support than has been the case for the implementation of other HW cadres, some costs can be substantial and can lead to variance in overall implementation costs. For example, Mullan and Frehywot found that the annual cost for training non-physicians in Tanzania varies considerably from one non-physician cadre to another, with costs ranging from US\$1,300 to US\$ 2,000 [36].

Sustainable training of WAJAs can be conducted by selecting training facilities at zonal, regional or district levels [37] such as the Clinical officer training centre, Kilosa. These institutions can be responsible for evaluating the need for training, conducting recruitment, and providing training [37]. This will reduce training problems that arise as a result of fragmented, piecemeal, or different training facilities that may lead to poor quality of training if they are not amenable to large training groups [38].

Currently, policy makers primarily focus on the training of doctors, nurses, and other mid-level health personnel [39]. This study may help policymakers allocate resources for training lower cadres of HW such as WAJAs to solve the existing human resource limitations in providing access to health services. The number of HW can be increased by promoting the WHO approach of recruiting and training local people, who will then reside and provide services in their respective localities.

The government should lead the scale- up and sustainability for a cadre of $\mathrm{CHW}$ in Tanzania using its existing health systems, training and administrative structures. This will have the potential to require fewer resources, as the estimated cost is less than that of non-government programmes seeking to achieve the same goal [40]. According to this model, the relative cost and time required to train, deploy and run advanced skilled cadres per year [36], compared to CHW, the CHWs has greater potential to be scaled-up from an economic perspective compared to other dispensing cadres to be deployed to the villages.

Our findings are comparable to results reported in a study on rural sub-Saharan Africa by McCord on 2013. These results showed that $\mathrm{CHW}$ average annual deployment costs were approximately US\$3,750 for rural sub-Saharan Africa, compared to US\$3,610 for WAJA. CHW average annual deployment cost per capita was US\$2.72 for rural sub-Saharan Africa compared to US\$1.16 for WAJA [40]. This can be manageable at the community level, if the health manager at the districts level will prioritize this and sensitize to community ownership.

\section{Limitations}

Training curriculum development was deemed to be a once only project activity that would contribute to national training plans. The analysis bounded to two cohorts of training, covering a total of 113 WAJA. For this reason, the study did not take into account the incremental salary and benefits associated with the contribution of the lead trainer and the training supporting staff that developed the curriculum. Also, the infrastructure associated with training sessions has not been included in costing. WAJA family additional support costs for incidental spending and clothing are not factored into estimates of incremental WAJA costs. Lastly, the scaling up analysis did not account for the attrition rate, this can be one of the factors hindering the sustainability of the program at large scale.

\section{Conclusion}

To sustainably train, deploy and run a cadre of communitybased health personnel, the government must take into consideration the factors that may hinder the continuous production of HWs according to demand for health care at the community level. These factors include whether the number of HWs being trained and deployed will be sufficient to meet the demand for these health personnel, and whether there is a need to build new schools or expand existing training facilities to meet expected requirements.

\section{Endnotes \\ ${ }^{1}$ Bank of Tanzania 2011 report (1 USD = TSH 1510).}

\section{Abbreviations}

CHW, Community Health Workers; HDSS, Health and Demographic Surveillance Systems; HW, Health Workers; IHI, Ifakara Health Institute; MDGs, Millennium Development Goals; MNCH, Maternal, Newborn, and Child Health; MoHSW, Ministry of Health and Social Welfare; $\Pi \mathrm{TCH}$, Tanzanian Training Centre for International Health; WAJA, "Wawazesha wa afya ya Jamii"; WHO, World Health Organization

\section{Acknowledgements}

We sincerely thank the study participants, the Tanzania Training Centre for International Health management, the clinical officer training centre - Kilosa, and members of the Connect project, including Ruth Wilson, Awena Malendo, Dominick Mboya, Doroth Maganga, Mustafa Njozi and Samweli Likasi, for their cooperation during data collection. We also thank Mallory Sheff and Allison Stone for editing the final draft. The Connect Project is funded by the Doris Duke Charitable Foundation and Comic Relief.

\section{Authors' contributions}

KT conceptualized the research question, designed the study, collected data, executed data analysis and drafted the manuscript. AMK and FM participated in designing the study and provided critical review of the manuscript. $\mathrm{AH}$ and JFP designed the primary study and critically reviewed and revised the manuscript together with $A E, C D B$ and SP. All the authors read and approved the final draft of the manuscript.

\section{Competing interests}

The authors declare that they have no competing interests. All authors reviewed the manuscript prior to publication. The funders had no role in the design of this study; collection, management, analysis and interpretation of the data or the conduct of this study or preparation or approval of the manuscript. 


\section{Ethics approval and consent to participate}

This study was approved by the Columbia University Medical Center Institutional Review Board (Protocol AAAF3452), by the National Institute for Medical Research's Medical Research Coordinating Committee (NIMR-CC) (NIMR/HQ/R.8a/Nol.IX/1203), and by the Ifakara Health Institute's Institutional Review Board (IHI/RB/No. 16-2010). For participant from TTCIH as trainer of CHA we received word consents before interview and for Clinical officer training centre - Kilosa we wrote a letter requesting visiting institution and prior discussion we received word consent.

\section{Author details}

${ }^{1}$ Ifakara Health Institute, P.O. Box 78373, Dar es Salaam, Tanzania. ${ }^{2}$ Heilbrunn Department of Population and Family Health, Mailman School of Public Health, Columbia University, 60 Haven Avenue (B2), New York, NY 10032, USA. ${ }^{3}$ Tanzanian Training Centre for International Health, P.O. BOX 39, Ifakara, Tanzania.

Received: 31 August 2015 Accepted: 24 June 2016

Published online: 08 July 2016

\section{References}

1. WHO. Global health work force alliance, Global Experience of Community Health Workers for Delivery of Health Related Millennium Development Goals. 2006.

2. WHO. Global health work force alliance, Scaling up saving lives. 2008b.

3. Kinfu Y, Mercer HS, Dal Poz MR, Evans DB. Estimating inflows and outflows of health service providers in sub-Saharan Africa, Evidence and Information for Policy World Health Organization Geneva, March 2006. 2006.

4. Sikika. Human Resources for Health in Tanzania Deployment Tracking Survey -Global Equity Initiative. 2010. http://sikika.or.tz/wp-content/ uploads/2013/09/human-resources-for-health-in-Tanzania.pdf.

5. Juma A, Kangalawe AG, Dalrymple E, Kanyenda T. Case Study \#9-11, "Brain Drain of Health Professionals in Tanzania". In: Per Pinstrup-Andersen and Fuzhi Cheng (editors), "Food Policy for Developing Countries: Case Studies.". 2012.

6. Kinfu Y, Dal Poz MR, Mercer H, Evans DB. The health worker shortage in Africa: are enough physicians and nurses being trained? Bull World Health Organ. 2009;87:161-244.

7. Naicker S, Plange-Rhule J, Tutt RC, Eastwood JB. Shortage of healthcare workers in developing countries-Africa. Ethn Dis. 2009;19(1 Suppl 1):S1-60. 4. http://www.ncbi.nlm.nih.gov/pubmed/19484878

8. MoHSW. Human Resource for Health Strategic Plan 2008 - 2013. 2008a Dar es Salaam.

9. MOHSW. Human Resources for Health country profile 2011. 2012.

10. Unicef. Committing to Child Survival: A promise renewed. 2012.

11. WHO, U., UNFPA, World Bank. Trends in maternal mortality 1990 to 2010. 2012

12. MoHSW. United Republic of Tanzania, Mortality and Health Monograph. 2015

13. Mkoka DA et al. Availability of drugs and medical supplies for emergency obstetric care: experience of health facility managers in a rural District of Tanzania. BMC Pregnancy Childbirth. 2014;14:108.

14. Freeman $P$ et al. Accelerating progress in achieving the millennium development goal for children through community-based approaches. Global Public Health. 2009;7(4):400-19.

15. Penfold $\mathrm{S}$ et al. Staff experiences of providing maternity services in rural southern Tanzania - a focus on equipment, drug and supply issues. BMC Health Serv Res. 2013;13(1):1-9.

16. Mbilinyi D, Daniel ML, Lie GT. Health worker motivation in the context of HIV care and treatment challenges in Mbeya Region, Tanzania: A qualitative study. BMC Health Serv Res. 2011;11:266.

17. McPake $B$ et al. Cost-effectiveness of community-based practitioner programmes in Ethiopia, Indonesia and Kenya. Bull World Health Organ. 2015;93(9):631-639A

18. Bhutta ZA et al. Alma-Ata: Rebirth and Revision 6 Interventions to address maternal, newborn, and child survival: what difference can integrated primary health care strategies make? Lancet. 2008;372(9642):972-89.

19. George A et al. Community case management of childhood illness in Nicaragua: transforming health systems in underserved rural areas. J Health Care Poor Underserved. 2009;20(4 Suppl):99-115.

20. Zachariah $\mathrm{R}$ et al. Task shifting in HIV/AIDS: opportunities, challenges and proposed actions for sub-Saharan Africa. Trans R Soc Trop Med Hyg. 2009; 103(6):549-58
21. Andy H. Community health-workers: scaling up programmes. Lancet. 2007; 369(Issue 9579):2058-9.

22. Lassi ZS et al. Evidence from community level inputs to improve quality of care for maternal and newborn health: interventions and findings. Reprod Health. 2014;11(11 Suppl 2):S2.

23. Christopher JB et al. Thirty years after Alma-Ata: a systematic review of the impact of community health workers delivering curative interventions against malaria, pneumonia and diarrhoea on child mortality and morbidity in sub-Saharan Africa. Hum Resour Health. 2011;9(1):27.

24. Mayombana C et al. Training of village health workers in Tanzania; a comparison of two approaches. Trop Doct. 1990;20(2):63-7.

25. Frankel S. The community health worker: effective programmes for developing countries. Oxford University Press: 1992. http://trove.nla.gov.au/work/ 21062890? q\&versionld $=25069855$.

26. MoHSW. Health Sector Strategic Plan III "Partnerships for Delivering the MDGs" July 2009 - June 2015. 2008b.

27. MoHSW. Primary Health Services Development Programme- MMAM 2007 2017. 2007.

28. Prabhjot Singh EA. One Million Community Health Workers, Techical task force report. 2012. http://www.millenniumvillages.org/uploads/ReportPaper/ $1 \mathrm{mCHW}$ _TechnicalTaskForceReport.pdf.

29. Mubi M et al. Malaria Rapid Testing by Community Health Workers Is Effective and Safe for Targeting Malaria Treatment: Randomised Cross-Over Trial in Tanzania. PLoS One. 2011;6(7):e1975.

30. Johns B, Baltussen R, Hutubessy R. Programme costs in the economic evaluation of health interventions. Cost Eff Resour Alloc. 2003;1(1):1.

31. Amon E et al. Role of condom negotiation on condom use among women of reproductive age in three districts in Tanzania. BMC Public Health. 2012; 12(1):1097.

32. Ramsey K et al. The Tanzania Connect Project: a cluster-randomized trial of the child survival impact of adding paid community health workers to an existing facility-focused health system. BMC Health Serv Res. 2013;13 Suppl 2:S6.

33. Kurowski $\mathrm{C}$ et al. Scaling up priority health interventions in Tanzania: the human resources challenge. Health Policy Planning. 2007;22(3):113-27.

34. O'Brien MJ et al. Role development of community health workers: an examination of selection and training processes in the intervention literature. Am J Prev Med. 2009:37(6 Suppl 1):S262-9.

35. Kasteng $\mathrm{F}$ et al. Valuing the work of unpaid community health workers and exploring the incentives to volunteering in rural Africa. Health Policy Plan. 2016;31(2):205-16.

36. Mullan F, Frehywot S. Non-physician clinicians in 47 sub-Saharan African countries. Lancet. 2007:370(9605):2158-63.

37. Javanparast $S$ et al. The experience of community health workers training in Iran: a qualitative study. BMC Health Serv Res. 2012;12(1):291.

38. Heggenhougen K, Vaughan P, Muhondwa EPY, Rutabanzibwa-Nagaiza J. Community Health Workers: The Tanzanian Experience. Oxford: Oxford University Press; 1987.

39. Dovlo D. Using mid-level cadres as substitutes for internationally mobile health professionals in Africa. A desk review. Hum Resour Health. 2004;2(1):7.

40. McCord GC, Liu A, Singh P. Deployment of community health workers across rural sub-Saharan Africa: financial considerations and operational assumptions. Bull World Health Organ. 2013;91(4):244-53B.

\section{Submit your next manuscript to BioMed Central and we will help you at every step:}

- We accept pre-submission inquiries

- Our selector tool helps you to find the most relevant journal

- We provide round the clock customer support

- Convenient online submission

- Thorough peer review

- Inclusion in PubMed and all major indexing services

- Maximum visibility for your research

Submit your manuscript at www.biomedcentral.com/submit
Biomed Central 